\title{
EXPERIMENTAL STUDY OF MECHANICAL LOSSES OF SINGLE-CYLINDER SPARK-IGNITED ENGINE
}

\author{
Carlos A ROMERO, Edison HENAO, Juan RAMÍREZ
}

\author{
Universidad Tecnológica de Pereira \\ cromero@utp.edu.co, edisonhenao@utp.edu.co, juandaviramireza@utp.edu.co
}

\begin{abstract}
In this study, the mechanical losses of a single-cylinder spark-ignited Robin EY15 engine were experimentally determined and analysed by the indicated method. The effects of the load and speed on the mechanical loss balance were also analysed. The tests were conducted on a test bench equipped with a DC motor generator at speeds between 1500 and $4800 \mathrm{~min}^{-1}$ and three load levels of 25, 50, and 100\%. The results showed that the mechanical efficiency ranges between $22.5 \%$ and $83.2 \%$ for the tested engine and the evaluated operation points, attaining the highest efficiency under the full load and $2100 \mathrm{~min}^{-1}$. However, at this load level, the efficiency is reduced to $29 \%$ with the increase in the rotation speed. Concurrently, the pumping losses contribute up to $58.7 \%$ of the total losses, which indicates that their contribution is even higher than the sum of the other components under low load conditions. However, as the load increases, this contribution decreases to $18 \%$ for lower rotation regimes. In addition, the experimental results of the total mechanical losses were compared with some numerical correlations found in the literature. Finally, some empirical correlations were proposed for the mechanical efficiency calculation of the tested engine.
\end{abstract}

Keywords: Internal combustion engines; Friction losses; Pumping losses; Mechanical efficiency.

\section{INTRODUCTION}

Internal combustion engines (ICEs) are machines that convert chemical energy into mechanical work by the combustion process [1]. However, only approximately $25 \%$ of the chemical energy that enters an engine is transformed into useful work in the output shaft [2]. The remainder of the energy is dissipated as heat to the environment through the exhaust gases, cooling system, and engine housing.

Only a fraction of the energy provided by the fuel is transformed into work in the combustion chamber (indicated work). However, approximately $20 \%$ of the indicated work is required to overcome the engine mechanical losses when operating at full load or $100 \%$ when it operates at no load [3]. The mechanical performance of the engines presents rotational speed and load level dependence. The major contributors to the mechanical losses are the drive devices of the auxiliary systems, which account for $15-25 \%$ of the total mechanical losses, and the friction of all the kinematic pairs of the engine, accounting for 45-65\% [4]. The latter, in turn, is mainly contributed by the Piston/rings group, accounting for $50-68 \%$ of the friction, the crankshaft, amounting to $25-35 \%$, and the camshaft, accounting for $10-20 \%$ [5]. In addition, the pumping in the intake and exhaust phases contributes $15-30 \%$ of the total mechanical losses for diesel engines [4] and up to 50\% for gasoline engines [5]. By reducing mechanical losses, it is possible to improve engine performance, reduce fuel consumption and $\mathrm{CO} 2$ emissions, extend durability, and thus, reduce operating costs [2],
[6]-[9]. However, evaluating the techniques for reducing losses, such as development of lubricants with better tribological properties and friction modifiers, surface treatments with better finish, and engine downsizing, requires experimental tests, even when numerical methodologies are used [4], [7], [10],[11].

There are different techniques for experimentally determining the mechanical performance of ICEs. Some methods allow studying mechanical losses under motoring conditions. However, owing to the absence of combustion, the loads and temperatures differ from the real operating ones, affecting the lubrication regimes of the kinematic pairs [12]-[15]. By the indicated method, which is extensively used and considered to have high precision, total mechanical losses are determined during engine operation. Therefore, the thermal and tribological conditions correspond to the normal operation conditions (real conditions) [1], [12], [13], [16], allowing observation of the speed and load variations effects on the mechanical performance. In addition, pumping losses can be calculated by analysing the intake and exhaust processes in the indicated diagram [4], [17]. The minimum variables required to implement the indicated method are the incylinder pressure, torque in the output shaft, and angular crankshaft position [3], [11]-[13], [18],

Using the indicated method, several researchers determined the mechanical losses of ICEs. Skjoedt et al. [18] analysed the lubricating base, oil viscosity, and friction modifier effect on the mechanical losses and fuel consumption of a $2.5-\mathrm{L}$ six-cylinder engine at two operation points (1500 
$\min ^{-1}-90 \%$ load and $3000 \min ^{-1}-20 \%$ load). Noorman et al. [12] reported loss reduction by the addition of friction modifiers in a six-cylinder engine during various electronically controlled operating routines. Tests were conducted at three engine speeds (1500, 2000, and $3000 \mathrm{~min}^{-1}$ ) and loads between $1 / 12$ and $3 / 4$ of the throttle opening. Mufti [19] determined the total mechanical losses of a single-cylinder Ricardo-Hydra overhead camshaft engine. In that study, tests were conducted at speeds between 800 and $2000 \mathrm{~min}^{-1}$ and loads of $1 / 4$ and $1 / 2$ of the throttle opening. Moreover, the effects of oil viscosity, oil temperature, and friction modifiers on the losses were analysed. CruzPeragon et al. [3] determined the mechanical losses and mechanical performance of a single-cylinder diesel engine operating at speeds between 1600 and $2800 \mathrm{~min}^{-1}$ and a three-cylinder spark ignition engine operating at speeds between 2500 and 6000 $\min ^{-1}$ under variation in the load. The results showed that under a constant load, their mechanical efficiency decreases as the speed increases. In contrast, at a constant speed, the mechanical efficiency increases with increasing loads. However, from the above study, it is impossible to conclude the behaviour or contribution of the pumping losses. Wakuri et al. [16] analysed the pumping losses of a single-cylinder engine by varying the speed and the load, concluding that the contribution of the pumping losses is $10-20 \%$ of the total mechanical losses and that they are affected mainly by the engine speed. However, the experiment was conducted in a diesel engine, where the pumping losses are not considerably affected by the load variation because it does not have a throttle body in the intake. In addition, the total mechanical losses were determined by the run-out method, which is utilized in the absence of combustion. Gish et al. [15] analysed the mechanical performance, friction, and pumping losses of a four-cylinder spark ignition engine under two compression ratios (7:1 and 12: 1) and five loads (3, $25,50,75$, and $100 \%)$. The results showed that for a constant regime, the load increase and a higher compression ratio increase the in-cylinder pressure causes a greater friction from the in-cylinder pressure increase. This, in turn, produces a larger contact force in each kinematic pair of the crankpiston mechanism. Although, the mechanical efficiency was enhanced and the pumping losses were decreased owing to the reduction in the restrictions caused by the throttle valve at higher loads, this study was conducted at $1600 \mathrm{~min}^{-1}$ only.

Numerical study of the mechanical losses is a cost-effective alternative, which makes it possible to predict the losses by empirical correlations based on engine operating characteristics, such as the crankshaft speed, average piston speed, pressure in the intake duct, maximum in-cylinder pressure, and main engine measures [14], [20]-[22]. In addition, numerical studies involve mathematical modelling based on the engine dynamics, kinematics, and tribological behaviour [4], [9], [11], [20], [21], [25] or application of black box models trained only with experimental data [10]. It should be clarified that the calibration of a model is subject to the particular characteristics of the engine.

In the present study, the total mechanical losses, pumping losses, sum of the friction and auxiliaries, and mechanical efficiency of a single-cylinder spark ignition engine were determined and analysed using the indicated method under varying rotation speeds and loads. Furthermore, the experimental results were compared to those calculated using some correlations available in the literature. Finally, a few empirical correlations were proposed to determine the mechanical efficiency of the tested engine. The characteristics and configuration of the implemented test bench, test protocol, and acquisition and processing information are presented below.

\section{METHODOLOGY}

The following sections briefly describe the equipment used and the test bench configuration for achieving the technically acceptance of the installed instrumentation technically acceptable. Some instruments used were uncertified, and so, were characterized in university laboratories. The procedures for the execution of the test, data acquisition, and mechanical loss calculation using the indicated method are described. In the final section, some numerical correlations available in the literature for mechanical loss prediction are described, to which the experimental results were compared.

\subsection{Equipment and measuring instruments}

This section presents the technical characteristics of the Robin EY15 engine, motor generator, and load system resistance bank in Table 1. The technical data of the instrumentation and the data acquisition system are summarized in Tables 2 and 3 , respectively. The in-cylinder and intake pressure values reported in this work are manometric.

\subsection{Test bench configurations}

This section presents the integration of the test bench. The Robin EY15 engine, a torque metre, and motor-generator shafts were coupled, as shown in Figure 1. The intake duct was extended, and a large-volume tank was installed to suppress the intake air pulsations and improve the inlet mass flow measurement. The measuring instruments were installed at the illustrated locations, and the information was transferred to the corresponding signal acquisition system. The data were stored in a computer, except the engine fuel consumption, which was determined by measuring using a chronometer as the time to consume a known volume of fuel contained in a burette. 
Table 1. Technical data of Robin EY15 engine and load system.

\begin{tabular}{|c|c|}
\hline \multicolumn{2}{|c|}{ Robin EY15 engine } \\
\hline Type & $\begin{array}{c}\text { vertical, single-cylinder, side } \\
\text { valve, spark ignited, air cooled }\end{array}$ \\
\hline Bore x Stroke & $63 \mathrm{~mm}$ x $46 \mathrm{~mm}$ \\
\hline Displacement & $143 \mathrm{~cm}^{3}$ \\
\hline Compression ratio & $6,3: 1$ \\
\hline Max power & $2,6 \mathrm{~kW}$ at $4000 \mathrm{~min}^{-1}$ \\
\hline Max torque & $6,7 \mathrm{Nm}$ at $2800 \mathrm{~min}^{-1}$ \\
\hline Min fuel comsumption & $380 \mathrm{~g} / \mathrm{kWh}$ \\
\hline Lubrication type & splash \\
\hline Oil (Quantity) & $10 \mathrm{~W} 40$ (600 ml) \\
\hline Fuel system & Horizontal carburettor \\
\hline Aspiration type & Naturally \\
\hline Fuel & Gasoline \\
\hline \multicolumn{2}{|c|}{ Motor generator } \\
\hline Brand/series & pacific scientific/ SR series \\
\hline Type & DC permanent magnet \\
\hline Voltage/current & $120 \mathrm{~V} / 8,7 \mathrm{~A}$ \\
\hline Rotation speed & $3200 \mathrm{~min}{ }^{-1}$ \\
\hline Max power & $2.0 \mathrm{HP}$ \\
\hline Electrical resistance bank \\
\hline Loads & 20 fixed electrical resistance \\
\hline Max current & $25 \mathrm{~A}$ \\
\hline
\end{tabular}

Table 2. Technical data of measuring instruments.

\begin{tabular}{|c|c|c|c|}
\hline Device & Range & Sensibility & Resolution \\
\hline $\begin{array}{l}\text { Kistler } 7061 \mathrm{~B} \\
\text { pressure sensor }\end{array}$ & $0-250$ bar & $-80 \mathrm{pC} / \mathrm{bar}$ & \\
\hline $\begin{array}{c}\text { kistler } 5165 \mathrm{~A} \\
\text { charge } \\
\text { amplifier }\end{array}$ & $\begin{array}{l}0-10 \mathrm{~V} \\
\text { (output) }\end{array}$ & $0,04 \mathrm{~V} / \mathrm{bar}$ & \\
\hline $\begin{array}{l}\text { Futek TRS705 } \\
\text { torque sensor } \\
\text { with rotary } \\
\text { encoder }\end{array}$ & $\pm 50 \mathrm{Nm}$ & $0,1 \mathrm{~V} / \mathrm{Nm}$ & $\begin{array}{c}1^{\circ} \\
\text { (encoder) }\end{array}$ \\
\hline $\begin{array}{l}\text { IHH500 torque } \\
\text { processor }\end{array}$ & $\begin{array}{c}0-5 \mathrm{~V} \\
\text { (output) }\end{array}$ & $0,1 \mathrm{~V} / \mathrm{Nm}$ & \\
\hline $\begin{array}{c}\text { Omron rotary } \\
\text { encoder }\end{array}$ & $720 \mathrm{P} / \mathrm{R}$ & & $0,5^{\circ}$ \\
\hline MAP sensor & $10-300 \mathrm{kPa}$ & $\begin{array}{c}0,053 \\
\mathrm{~V} / \mathrm{kPa}\end{array}$ & \\
\hline MAF sensor & $<0,04 \mathrm{~kg} / \mathrm{s}$ & $\begin{array}{c}\text { non-linear } \\
\text { response }\end{array}$ & \\
\hline Burette & $0-100 \mathrm{ml}$ & & $1 \mathrm{ml}$ \\
\hline Chronometer & & & $0,01 \mathrm{~s}$ \\
\hline $\begin{array}{c}\mathrm{K} \text { type } \\
\text { thermocouples }\end{array}$ & $<1300{ }^{\circ} \mathrm{C}$ & & \\
\hline
\end{tabular}

\subsection{Experimental procedure}

This section presents a simple description of the experimental phase and the signal acquisition procedure. The Robin EY15 engine tests were conducted under variable speeds between 1500 and $4800 \mathrm{~min}^{-1}$ and loads of 25,50 , and $100 \%$ of the throttle opening. Because the resistance bank in the load system has fixed values of electrical resistance, achieved by setting the position of the throttle valve, the speeds are not regulated, instead they are determined by the load system. The tested operation points are described in greater detail in Table 4 . After setting each operation point, there was a waiting period of 2-3 min until the engine speed and different temperatures were stabilized. Regarding the data acquisition phase, two 10-s signals were captured, one each with NI9188 and NI6216 acquisition systems.

Table 3. Technical data of signal acquisition system.

\begin{tabular}{|c|c|c|c|}
\hline Device & $\begin{array}{c}\text { Data } \\
\text { acquisition } \\
\text { frequency }\end{array}$ & resolution & $\begin{array}{c}\text { Acquired } \\
\text { signals }\end{array}$ \\
\hline $\begin{array}{c}\text { NI } 9188 \\
\text { DAQ }\end{array}$ & $\leq 51,2 \mathrm{kS} / \mathrm{s}$ & $16 \mathrm{bits}$ & $\begin{array}{c}\text { in-cylinder } \\
\text { pressure, } \\
\text { torque, MAF, } \\
\text { MAP }\end{array}$ \\
\hline NI 9223 & $51,2 \mathrm{kS} / \mathrm{s}$ & 24 bits & $\begin{array}{c}\text { K type } \\
\text { thermocouples }\end{array}$ \\
\hline NI 9211 & $10 \mathrm{~S} / \mathrm{s}$ & 16 bits & $\begin{array}{c}\text { in-cylinder } \\
\text { pressure, } \\
\text { Omron encoder }\end{array}$ \\
\hline NI 6216 & $130 \mathrm{kS} / \mathrm{s}$ & \multicolumn{2}{|c}{} \\
\hline
\end{tabular}

Table 4. Test operating points.

\begin{tabular}{|c|c|}
\hline Load & Rotation speed [min-1] \\
\hline $25 \%$ & $1500,1900,2500,2800$ \\
\hline $50 \%$ & $\begin{array}{c}1600,2000,2900,3100,3550,4150,4450, \\
4800\end{array}$ \\
\hline $100 \%$ & $2100,3500,4200,4450,4800$ \\
\hline
\end{tabular}

\subsection{Mechanical losses calculation}

The simple mathematical relationships used to calculate the ICE mechanical losses and its performance characteristics are presented in this section. In addition, the indicated method is described.

The mechanical losses are defined as the difference between the energy available in the piston by the combustion process and the useful energy obtained at the output shaft, and they are mathematically expressed by the following equations [1]:

$$
W_{m}=W_{i}-W_{e}
$$

where $W_{m}$ : mechanical losses work, $W_{i}$ : indicated work, and $W_{e}$ : effective work.

The mechanical losses can also be expressed in terms of power using equation (2) and as mean effective pressures using equation (3).

$$
\omega i W_{m}=\omega i\left(W_{i}-W_{e}\right) \rightarrow N_{m}=N_{i}-N_{e}
$$

$$
\frac{W_{m}}{V_{d}}=\frac{\left(W_{i}-W_{e}\right)}{V_{d}} \rightarrow F M E P=I M E P-B M E P
$$

where $\omega$ : rotation frequency, $i$ : cycle parameter ( 0,5 for $4 \mathrm{~T}$ engine and 1 for $2 \mathrm{~T}$ engine), $N_{m}$ : mechanical loss power, $N_{i}$ : indicated power, $N_{e}$ : 


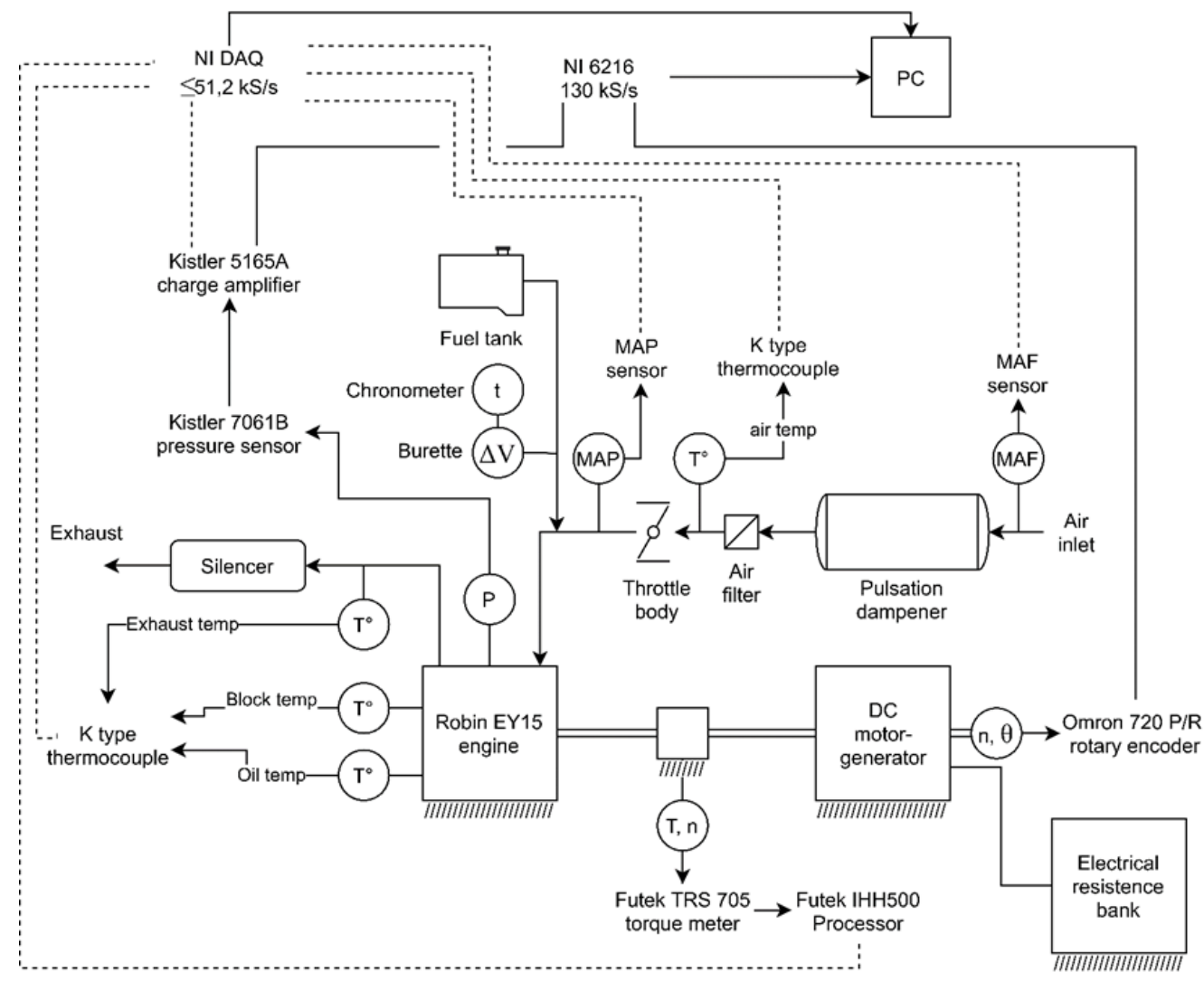

Fig. 1. Test bench scheme.

effective power, $V_{d}$ : displacement, $F M E P$ : friction mean effective pressure, IMEP: indicated mean effective pressure, and $B M E P$ : brake mean effective pressure.

The mechanical efficiency is calculated using equation (4).

$$
\eta_{m}=\frac{N_{e}}{N_{i}}
$$

where $\eta_{m}$ : mechanical efficiency.

The effective work and the BMEP are calculated by taking the average value of the torque signal during the 10-s data acquisition and using equation (6). The IMEP is calculated from the indicated diagram built by plotting the in-cylinder pressure, measured by a pressure sensor, versus the in-cylinder volume, calculated from the encoder signal. Figure 2 presents a representative indicated diagram showing the area corresponding to the indicated work, which is calculated using equation (5). The indicated method consists of calculating the mechanical losses causing the difference between the IMEP and BMEP. Using equation (5), the pumping work is calculated by integrating the area shown in Figure 2 and considering the closing angles of the intake and opening of the exhaust valves [4], [14]. Using this method, the pumping losses and the losses contributed by the friction and auxiliary contribution can be determined, as expressed in equation (7).

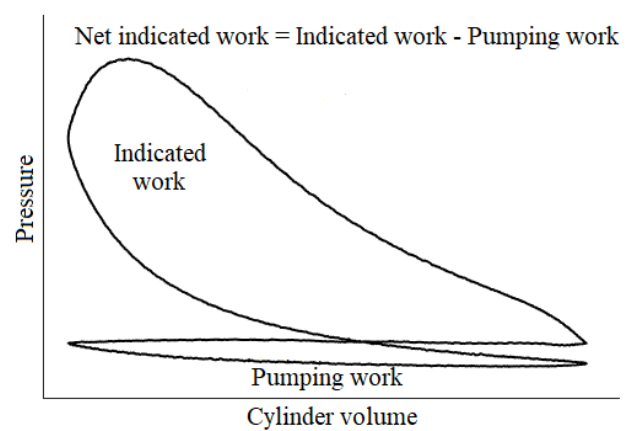

Fig. 2. Indicated diagram representation.

$$
W_{i}=\int P d V
$$

where $W_{i}$ : indicated work, $P$ : in-cylinder pressure, and $V:$ in-cylinder volume.

$$
W_{e}=\frac{2 \pi T}{i}
$$

where: $W_{e}$ : effective work, $T:$ output torque and $i:$ is 1 for $2 \mathrm{~T}$ engines or 0,5 for $4 \mathrm{~T}$ engines.

$$
N_{\text {fr }+ \text { aux }}=N_{m}-N_{p} \rightarrow R M E P+A M E P=F M E P-P M E P
$$

where $N_{f r+a u x}$ : friction and auxiliary power losses, $N_{p}$ : pumping loss power, $R M E P+A M E P$ : sum of rubbing mean effective pressure and auxiliary mean effective pressure, and PMEP: pumping mean effective pressure.

The effective performance parameters were supplemented with the specific fuel consumption 
and the net engine efficiency calculations using equations (8) and (9).

$$
g_{c}=\frac{\dot{m}_{\text {fuel }}}{N_{e}}
$$

where $g_{c}$ : specific fuel consumption and $\dot{m}_{\text {fuel }}$ : mass fuel flow.

$$
\eta_{e}=\frac{N_{e}}{\dot{Q}_{\text {fuel }}}=\frac{N_{e}}{\dot{m}_{\text {fuel }} L H V}
$$

where $\eta_{e}$ : net engine efficiency, $\dot{Q}_{\text {fuel }}$ : heat fuel flow, and $L H V$ : lower heat value.

\subsection{Comparative results}

This section briefly describes four empirical correlations reported by other authors that allow the FMEP calculation from the geometric and operating characteristics of the engine. Gish et al. [15] conducted experimental measurements of a fourcylinder spark ignition engine under different loads and at a constant speed of $1600 \mathrm{~min}^{-1}$, and found that the FMEP was only correlated to the maximum in-cylinder pressure. Millington and Hartles [14] correlated the results of several diesel engine mechanical losses with different cylinder bores, the compression ratio, and the average piston speed. The tests were conducted under motoring conditions. The empirical correlations by Yagi et al. [20] and Fujii et al. [21] depend on the main dimensions of the engine (such as the piston bore and stroke), diameters and number of connecting rod and crankshaft journals, and rotation speed. They differ in that in the equation by Yagi et al., the effects of the intake valve flow area and the oil viscosity are accounted. In both the studies, the losses of motorcycle engines, including some ultrahigh-speed engines, were evaluated for different displacements, number and arrangements of cylinders, and maximum speed. The tests were conducted under motoring, fully open throttle valve, and exhaust manifold removal conditions. Table 5 lists the equations of the above-mentioned

\begin{tabular}{|c|c|}
\hline Gish et al. & $\begin{array}{c}F M E P_{P a}=100000+0,0125 P_{\max } \\
P_{\max }: \text { maximum in-cylinder pressure in } \mathrm{Pa}\end{array}$ \\
\hline $\begin{array}{l}\text { Millington } \\
\& \text { Hartles }\end{array}$ & $\begin{array}{c}F M E P_{P S I}=A+\frac{7,0 n}{1000}+1,5\left(\frac{V_{p f}}{1000}\right)^{2} \\
A: \text { compression ratio, } V_{p f}: \text { mean piston speed } \mathrm{It} / \mathrm{min}, n: \text { rotation regime } \mathrm{min}^{-1}\end{array}$ \\
\hline Fujii et al. & $\begin{array}{c}F M E P_{M P a}=\left[3 \times 10^{-3} \cdot\left(n \times 10^{-3}\right)^{2}+0,2\right] \frac{\sqrt{S D_{m}}}{B} \\
S: \text { stroke, } B: \text { bore, } D_{m}: \text { crankshaft equivalent diameter. } \\
D_{m}: \frac{k_{c}\left[\sum_{1}^{m} D_{c j}+\sum_{1}^{y} D_{c p}\right]}{m+y} \\
k_{c}: \text { coefficient depending of cylinder number, } D_{c j}: \text { crank journal diameter, } D_{c p}: \text { crank pin diameter, } m: \\
\text { number of crank journals, } y: \text { number of crank pins. }\end{array}$ \\
\hline Yagi et al. & $\begin{array}{l}F M E P_{M P a}=\left[60 \times 10^{-9} \cdot\left(\frac{V_{c} n}{z}\right)^{2}+1,1 \times 10^{-9} n^{2}+0,0011 v+0,14\right] \frac{\sqrt{S D_{m}}}{B} \\
z: \text { effective intake valve flow area } \mathrm{m}^{2}, V_{c} \text { : displacement in } \mathrm{m}^{3}, v: \text { kinematic oil viscosity in cSt }\end{array}$ \\
\hline
\end{tabular}
correlations.

\section{RESULTS AND DISCUSSION}

In the following sections, the experimental results of the effective performance, IMEP, and mechanical efficiency of the tested engine are discussed, and subsequently the pumping and friction and auxiliary contributions are analysed. The experimental results are compared with the calculated results based on the correlations in Table 5 by analysing the difference percentage. Finally, three empirical correlations are proposed to calculate the Robin EY engine mechanical efficiency from experimental data and are again compared to the experimental data.

\subsection{Effective performance}

In this section, the characteristics of the effective performance of the engine are discussed. Figure 3 shows the plots of the torque, power, specific fuel consumption, net efficiency, and BMEP for each load and tested rotation regime. It is observed that for a given speed, the load increase causes the torque, power, efficiency, and BMEP to increase. The maximum torque and the BMEP are $5.14 \mathrm{Nm}$ and $4.5 \mathrm{bar}$, respectively, at $2100 \mathrm{~min}^{-1}$. The maximum power is $1.77 \mathrm{~kW}$ at $4200 \mathrm{~min}^{-1}$ at full load, $1.02 \mathrm{~kW}$ at $2900 \mathrm{~min}^{-1}$ at $50 \%$ load, and $0.32 \mathrm{~kW}$ at $1500 \mathrm{~min}^{-1}$ at $25 \%$ load. This indicates that the maximum power is obtained at higher speeds as the load increases because of the ability the engine to deliver higher torques. It can be seen that as the load increases, the specific consumption 
decreases; however, if the engine is accelerated to the fastest speed, the specific fuel consumption tends to increase, particularly for partial loads. This can be explained by the fact that the effective power drops rapidly at the highest speed and the engine continues to consume a considerable amount of fuel. The minimum consumption is $403.3 \mathrm{~g} / \mathrm{kWh}$ at $2900 \mathrm{~min}^{-1}$. The maximum and minimum net efficiency are 0.208 (20.8\%) and 0.03 (3\%), respectively, which suggests that $79.2 \%-97 \%$ of the energy provided by the fuel is dissipated as heat at the tested operating points. The net efficiency decreases owing to the decrease in the effective power and increase in the fuel consumption as the regime increases under any load. The maximum power and the torque characteristics are lower than those reported by the manufacturer whereas the minimum specific fuel consumption is higher. The maximum net efficiency obtained is lower than those of some engines with similar specifications. However, it must be noted that the effects of wear, mismatch, additional restrictions on the intake air flow, and air/fuel mixture calibration at each operation point affect the engine performance.

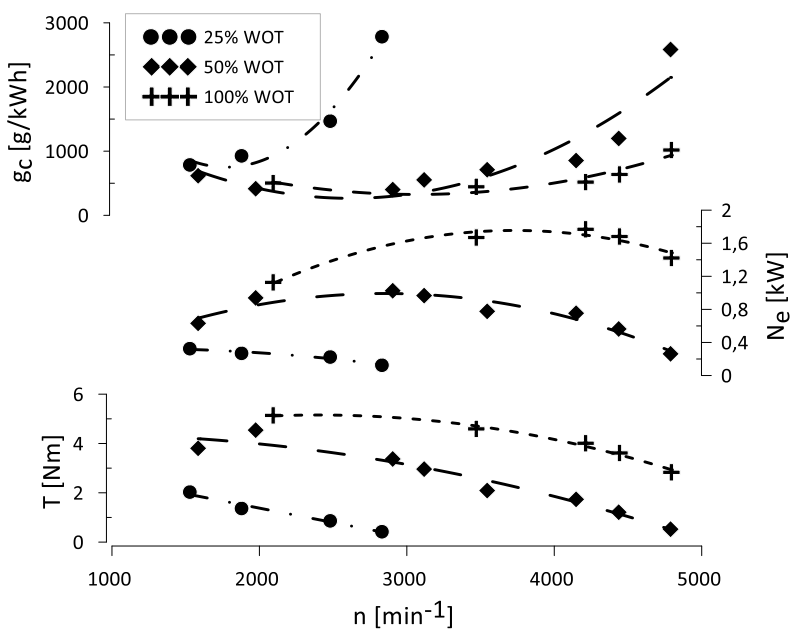

A

\subsection{Indicated performance}

In this section, the indicated parameters of the Robin EY15 engine are presented. The IMEP curves and $\mathrm{P}-\mathrm{V}$ diagrams constructed for 25, 50, and $100 \%$ loads and a speed close to $2000 \mathrm{~min}^{-1}$ are shown in Figure 4. It can be seen that the IMEP increases because the in-cylinder pressure increase with the load, so that more work is obtained in each cycle. It can be seen that the IMEP, like BMEP, decreases with speed, varying from 5.41 bar at 2100 min-1 to 4.21 bar at $4800 \mathrm{~min}^{-1}$ under the full load conditions. This occurs owing to the rapid decrease in the torque required to drive the load system generator and the decrease in the volumetric engine efficiency. The pumping work area in the $\mathrm{P}-\mathrm{V}$ diagram for $25 \%$ load is visibly larger than those for $50 \%$ and $100 \%$ load, which occurs mainly because the throttle valve position restricts the intake air flow and makes it difficult to fill the engine cylinder.

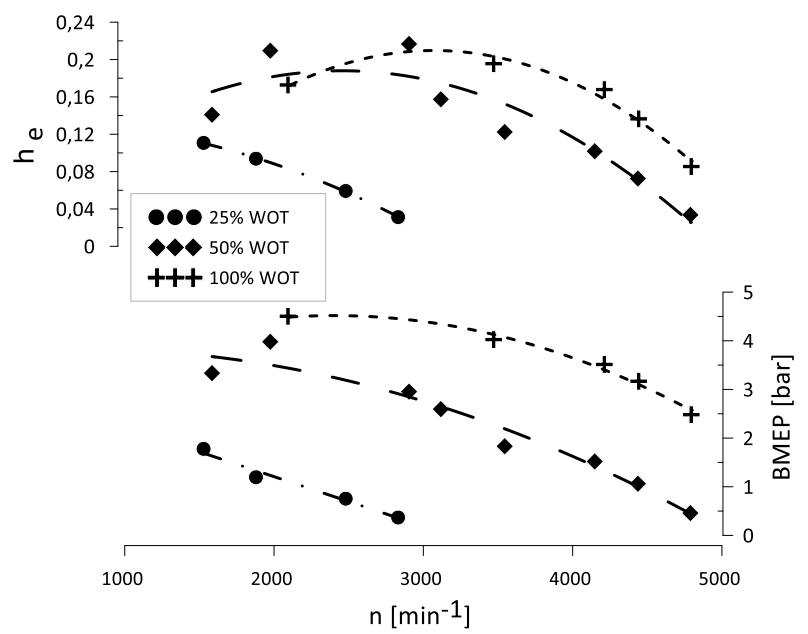

$\mathrm{B}$

Fig. 3. Effective Robin EY15 engine performance, A. engine performance, B. efficiency and BMEP.

\subsection{Total mechanical losses}

The engine mechanical performance plots and some operating conditions are shown below. Figure 5 shows the mechanical loss power, FMEP, mechanical efficiency, oil temperature, maximum in-cylinder pressure, and mean intake pressure. The power losses and FMEP increase mainly with the increase in the engine rotation speed. However, they slightly increase with the load caused by the in-cylinder pressure, which increases the friction forces between the rings, piston, and cylinder, particularly for speeds above $3000 \mathrm{~min}^{-1}$. For tests performed at $25 \%$ load, the oil temperature is low; therefore, the viscosity is high and influences the losses reported for this load level. The engine FMEP varies from 0.91 bar at $2100 \mathrm{~min}^{-1}$ to 1.73 bar at $4800 \mathrm{~min}^{-1}$ under the full load conditions, and this range is similar to the FMEP values reported by Yagi et al. [20] and Fujii et al.
[21] for single-cylinder engines with similar displacements. However, there are some differences because their results were obtained from motoring tests and at oil temperatures close to $80{ }^{\circ} \mathrm{C}$. It can be seen that the mechanical efficiency behaviour of the engine for a given speed improves with increasing load, reaching up to $83.2 \%$ at full load and $2100 \mathrm{~min}^{-1}$. However, owing to the increase in the losses and the reduction in the effective power, the mechanical efficiency decreases as the speed increases, regardless of the load level, decreasing up to $59 \%$ at full load or up to $22.5 \%$ at partial loads. This suggests that the mechanical losses consume $16.8 \%-77.5 \%$ of the indicated power at the tested operation points. These values are close to the range of $22 \%-70 \%$ reported by Cruz-Peragon et al. [3] for a single-cylinder diesel engine at the tested operation points. 


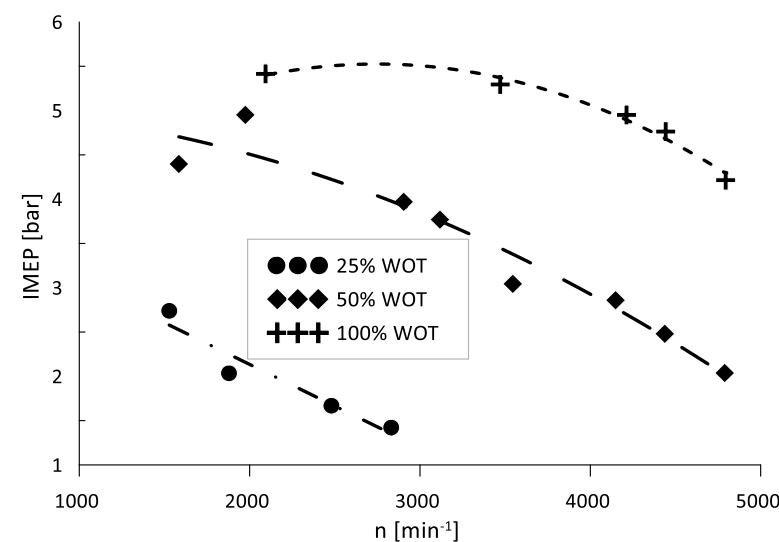

A

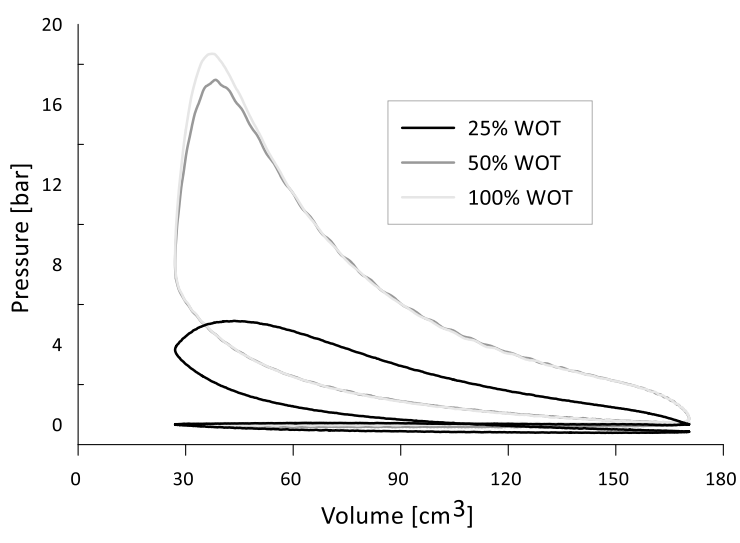

B

Fig. 4. Indicated performance. A. IMEP, B. P-V diagrams: $1900 \min ^{-1} 25 \%, 2000 \min ^{-1} 50 \%$ and $2100 \min ^{-1} 100 \%$.

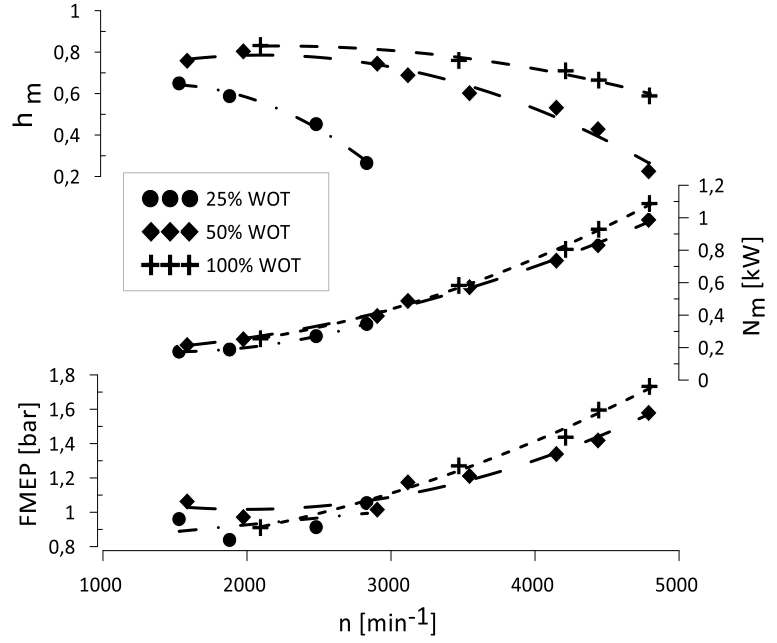

A

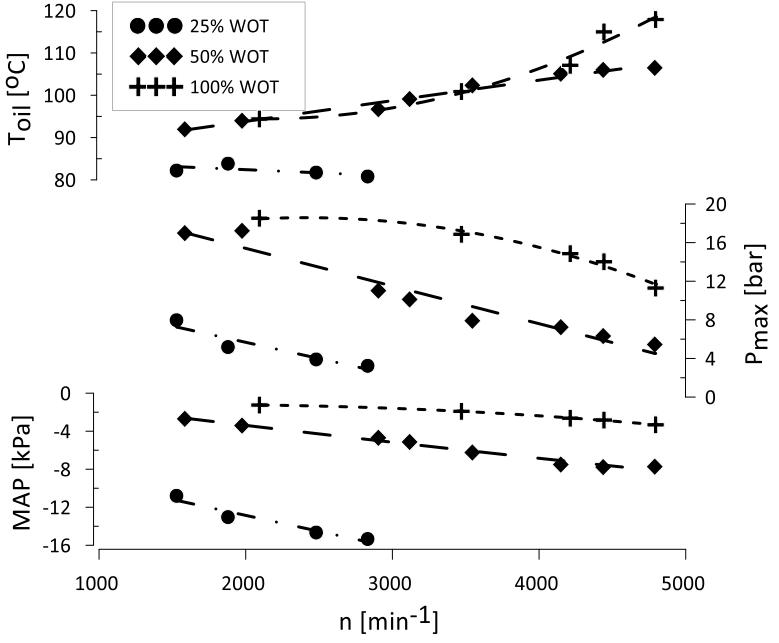

B

Fig. 5. Total mechanical losses, A. mechanical performance, B. operating conditions.

\subsection{Mechanical loss components}

This section presents the mechanical loss components obtained from the conducted experiments. In Figure 6, the curves of the power, mean effective pressure, and contributions of the pumping and friction and auxiliary loss components as percentages are shown. The pumping power increases with the rotation speed at any load level. However, it decreases with increasing load at a constant speed, which is related to the intake vacuum pressure increase with the air speed in the intake duct and decrease with the load caused by the throttle valve opening. Regarding the contribution of the PMEP over the FMEP, at full load, the pumping losses contribute between $18 \%$ at $2100 \mathrm{~min}^{-1}$ and $40.6 \%$ at $4200 \mathrm{~min}^{-1}$. However, under partial loads, the PMEP contribution increases, reaching a maximum of $58.8 \%$ at $2500 \mathrm{~min}^{-1}$ and $25 \%$ load. This is higher than maximum PMEP contribution of 50\% mentioned in the Wong and Tung review [5] and that of $38 \%$ reported by Gish et al. [15] at $1600 \mathrm{~min}^{-1}$ and $25 \%$ load for a four-cylinder spark ignition engine. However, it should be noted that the installed pulsation dampener reservoir restricts the air flow and produces a higher vacuum pressure. The friction and auxiliary contribution increases with the rotation speed and load increase, affected mainly by the in-cylinder pressure, which consequently intensifies the rings, pin, and piston skirt frictional force. The RMEP+AMEP over the FMEP contribution ranges between $82 \%$ at 2100 min- 1 and $58.4 \%$ at $4200 \mathrm{~min}^{-1}$ at full load. However, at partial loads, the contribution decreases to $41.2 \%$ at $2500 \mathrm{~min}^{-1}$ and $25 \%$ load.

\subsection{Correlations results}

In this section, the experimentally obtained FMEP are compared with those calculated from the empirical correlations of other researchers. The calculated FMEP engine curves for different speeds and loads are presented in Figure 7. The Millington and Hartles [14] correlation shows the maximum difference from the experimental results, reaching a $94.7 \%$ error, because the correlation was obtained for diesel engines tested under motoring conditions 


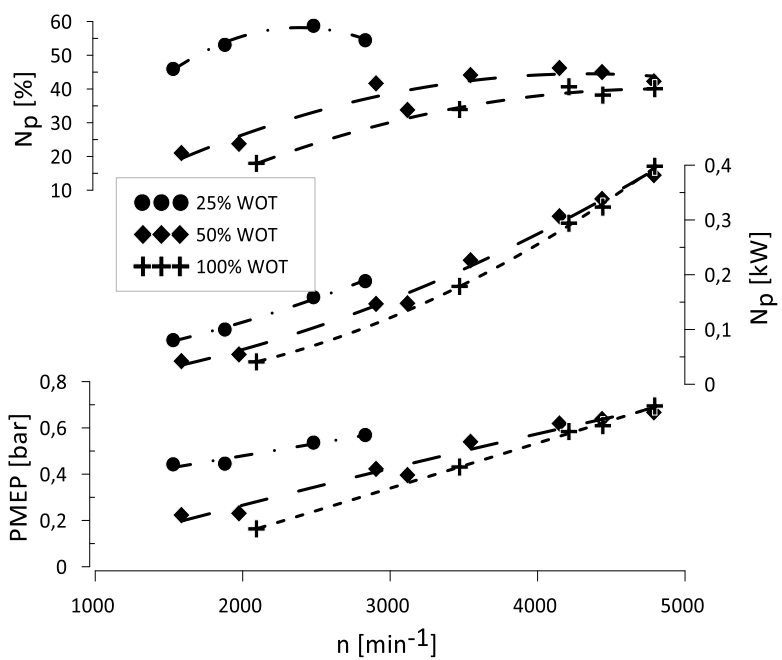

A

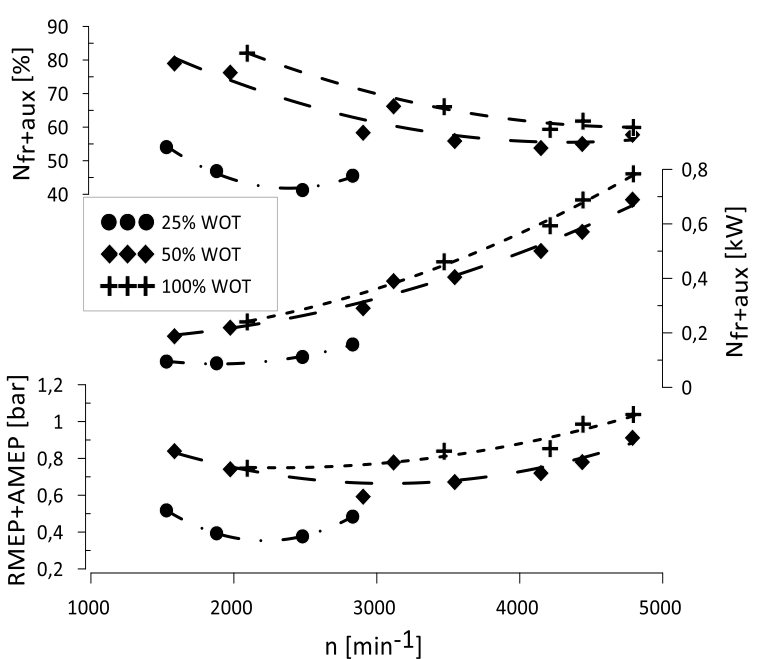

B

Fig. 6. Mechanical loss components. A. pumping, B. friction and auxiliaries.

and without a throttle valve. The Gish et al. [15] correlations is the best for $25 \%$ load, with differences ranging from $26.9 \%$ at $1900 \mathrm{~min}^{-1}$ to $1.8 \%$ at $2800 \mathrm{~min}^{-1}$. For $50 \%$ and $100 \%$ loads, the errors are lower than $32.3 \%$ and $34.2 \%$, respectively. Based on the correlation of Yagi et al. [20], the errors are lower than $32.8 \%, 23.4 \%$, and $18.24 \%$ for 25,50 , and $100 \%$ load levels, respectively. Finally, the Fujii et al. [21] correlation presents errors lower than $34.2 \%, 18.6 \%$, and $25.2 \%$ for 25,50 , and $100 \%$ load levels, respectively. The last two methods are better adjusted for rotation speeds higher than $3500 \mathrm{~min}^{-1}$ at full load, where the error is lower than $14.6 \%$, possibly because their conditions are the most similar to those tested in the current experimental study.

\subsection{Proposed mechanical efficiency correlations}

This section presents three-dimensional graphs of the mechanical efficiency as a function of the speed, BMEP, maximum in-cylinder pressure, and mean intake pressure, and surfaces fitted to the plotted points are also displayed in each graph. Finally, the surface equations are used to calculate the FMEP, and the computed values are compared with the experimental results. The surface graphs of the mechanical performance are shown in Figure 8.

The plots show that the mechanical performance decreases as the rotation speed increases. However, it improves with the increase in the BMEP, maximum in-cylinder pressure, and mean intake pressure, which are variables modified by varying the load. Equations (10)-(12) correspond to the illustrated surfaces, and the $\mathrm{R} 2$ value of each one is presented.

$$
\begin{gathered}
\eta_{m}=0,2594+0,2801 B M E P+1,605 \times 10^{-5} n \\
-0,03562 B M E P^{2}+7,162 \times 10^{-7} n B M E P \\
-9,716 \times 10^{-9} n^{2} \quad R^{2}=0,9764 \\
\eta_{m}=0,08982+0,09114 P_{\max }+6,083 \times 10^{-5} n \\
-3,356 \times 10^{-3} P_{\max }^{2}+3,547 \times 10^{-6} n P_{\max } \\
-2,616 \times 10^{-8} n^{2} \quad R^{2}=0,9511 \\
\eta_{m}=0,4763-0,03213 M A P+2,421 \times 10^{-4} n \\
-1,343 \times 10^{-3} M A P^{2}+1,674 \times 10^{-5} n M A P \\
-3,858 \times 10^{-8} n^{2} \quad R^{2}=0,9594 \\
F M E P=B M E P\left(\frac{1-\eta_{m}}{\eta_{m}}\right)
\end{gathered}
$$

The comparison of the FMEP calculated with equation (13) and the proposed correlations and the experimentally obtained FMEP can be seen in Figure 9 . Under $25 \%$ load, the correlations lead to error values less than $27.7 \%, 33.6 \%$, and $19.2 \%$. Under $50 \%$ load, they were less than $21.6 \%, 22.6 \%$, and $32.7 \%$, and under full load were less than $26.6 \%, 42.3 \%$, and $19.5 \%$, respectively, using equations (10)-(12), respectively. However, it should be noted that for $50 \%$ load at speeds between 2000 and $3550 \mathrm{~min}^{-1}$, the errors are less than $8.7 \%, 12.2 \%$, and $13.1 \%$. Moreover, for speeds greater than 3500 min-1 at full load, the errors are less than $6.1 \%, 8.5 \%$, and $19.5 \%$, with equations (10), (11), and (12), respectively. It should be noted that the correlations proposed in this section were obtained only from the Robin EY15 engine experimental results; therefore, they may need to be calibrated for other engine types. 

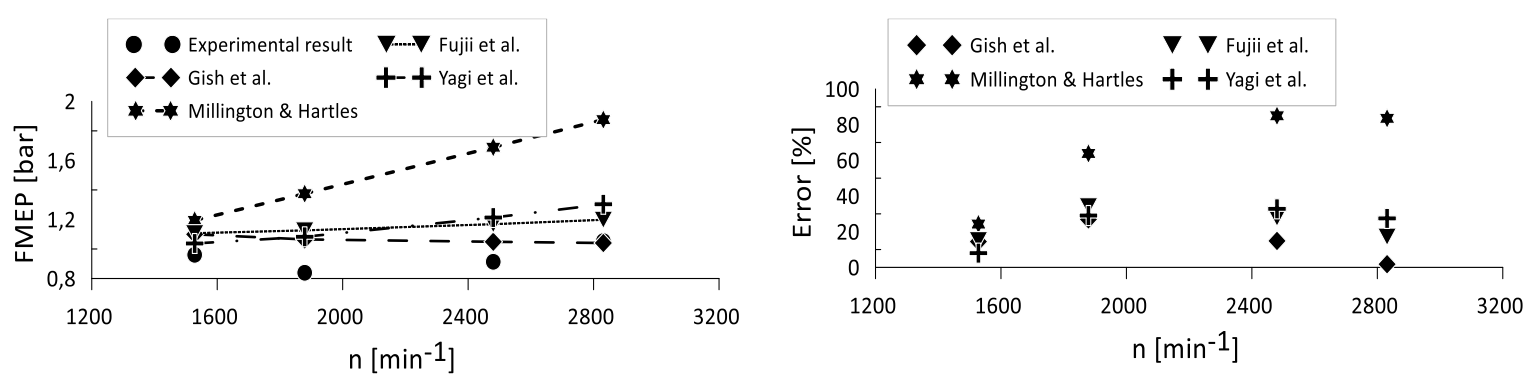

A
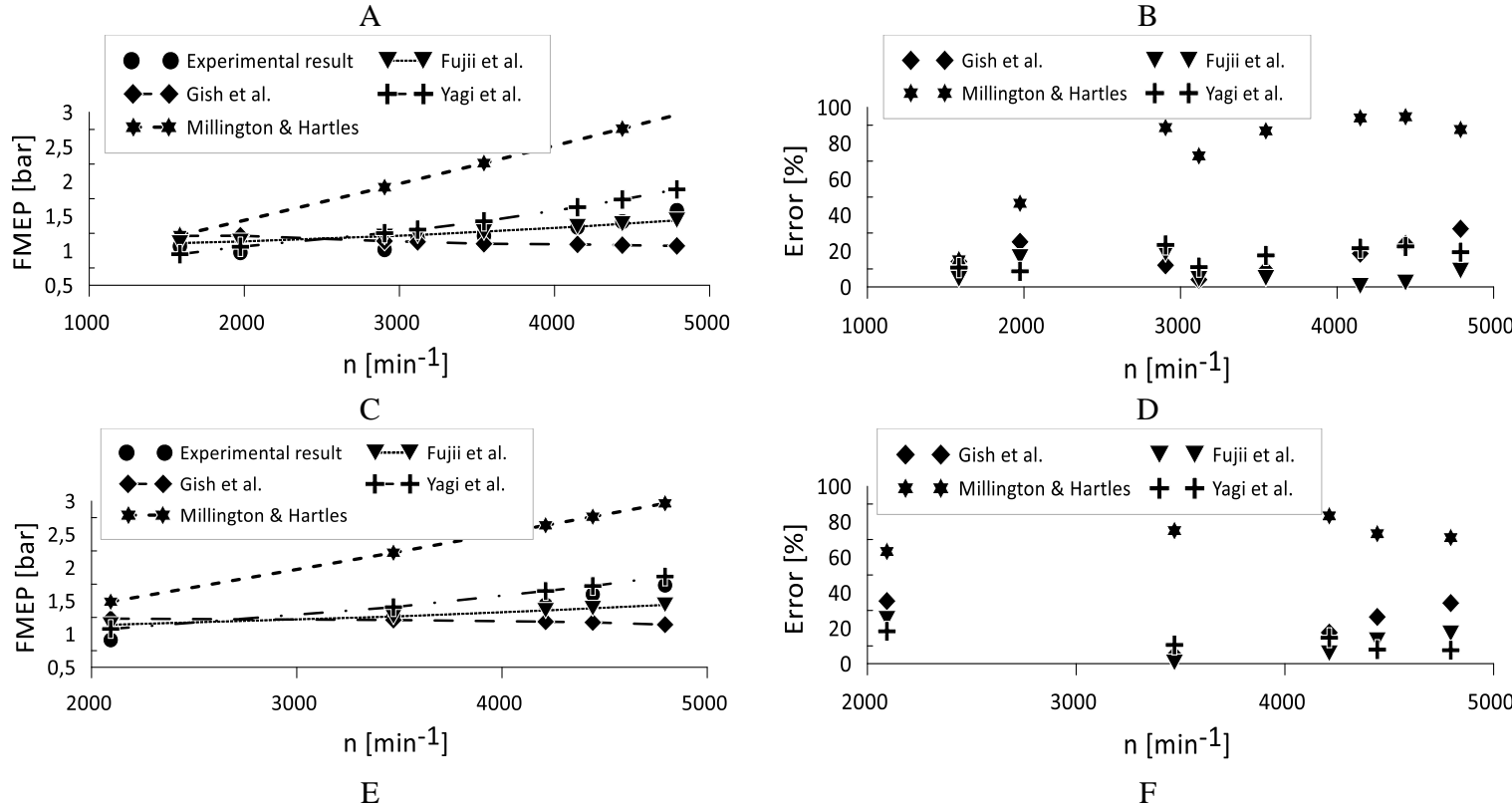

Fig. 7. FMEP correlations. A. $25 \%$ load, B. error percentage $25 \%$ load, C. $50 \%$ load, D. error percentage $50 \%$ load, E. $100 \%$ load, F. error percentage $100 \%$ load.

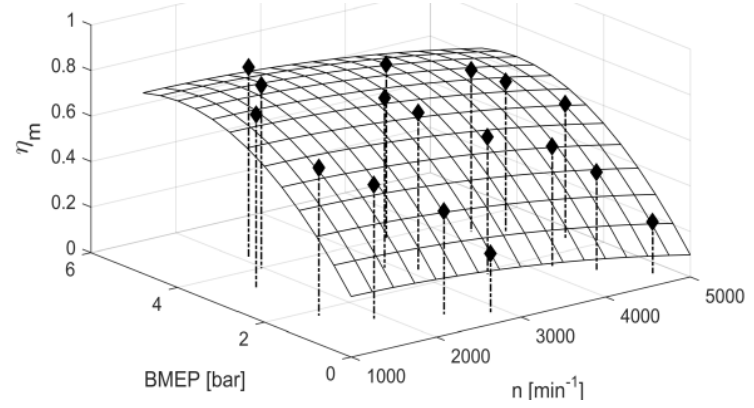

A

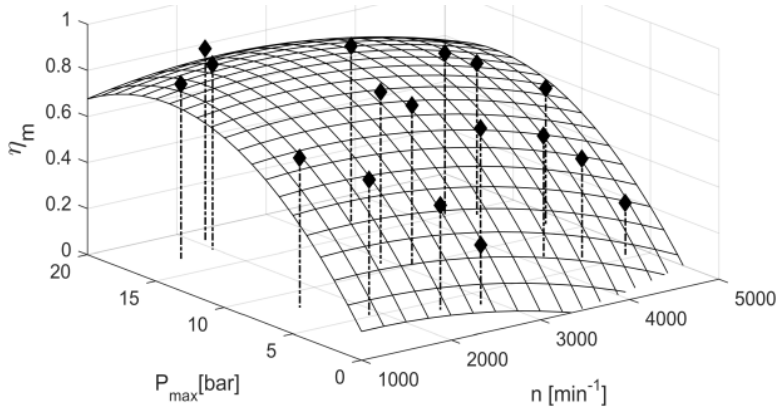

B

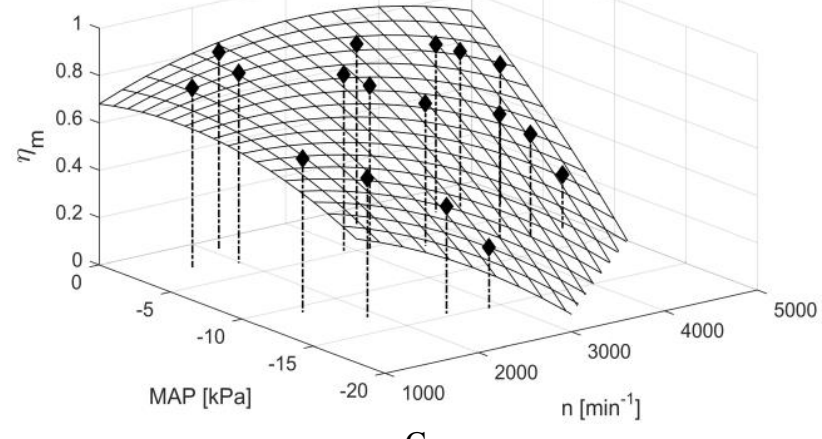

$\mathrm{C}$

Fig.8. Mechanical efficiency graphs in terms of rotation speed, A. BMEP, B. maximum in-cylinder pressure, C. mean intake pressure. 

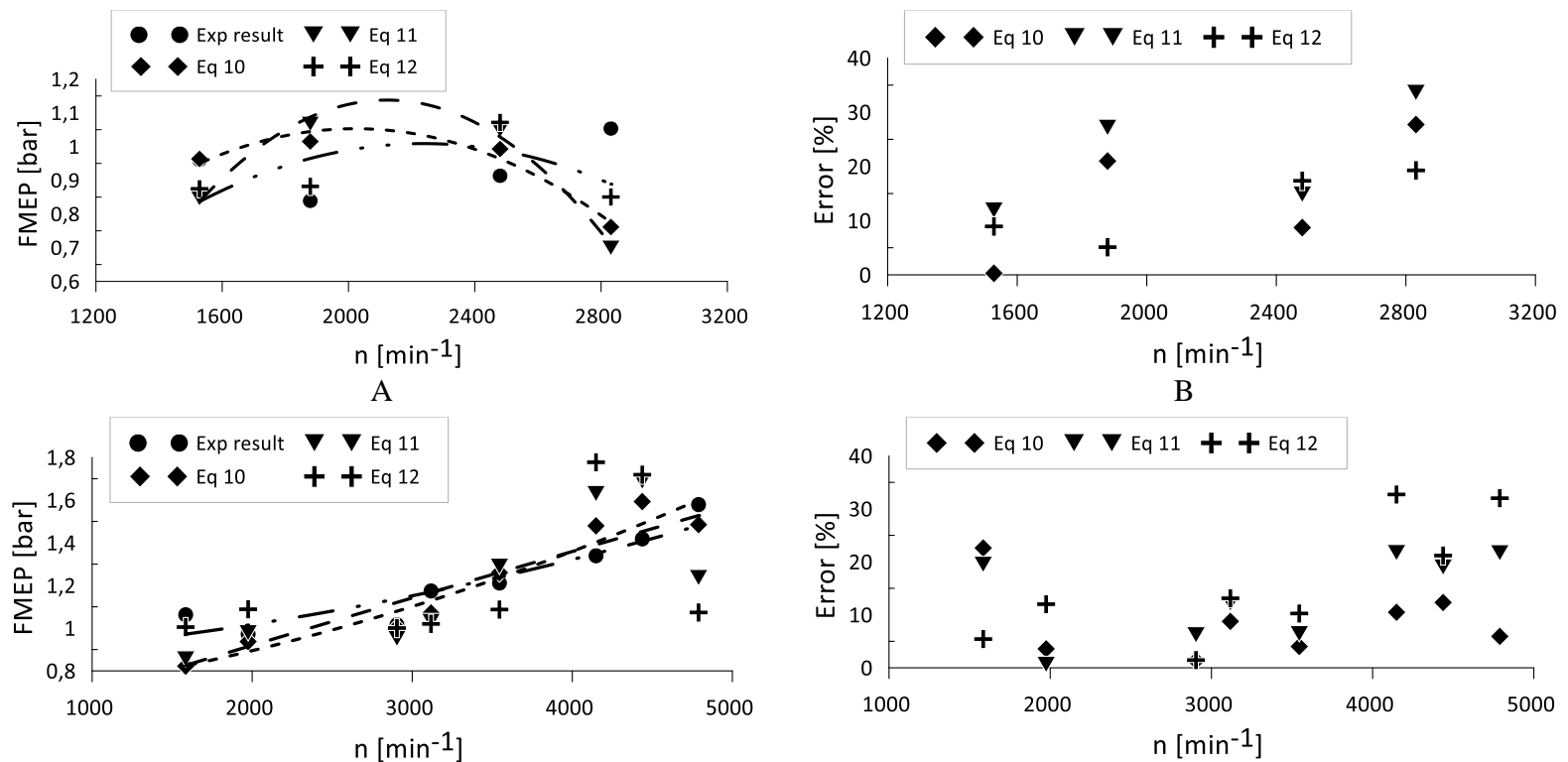

$\mathrm{C}$
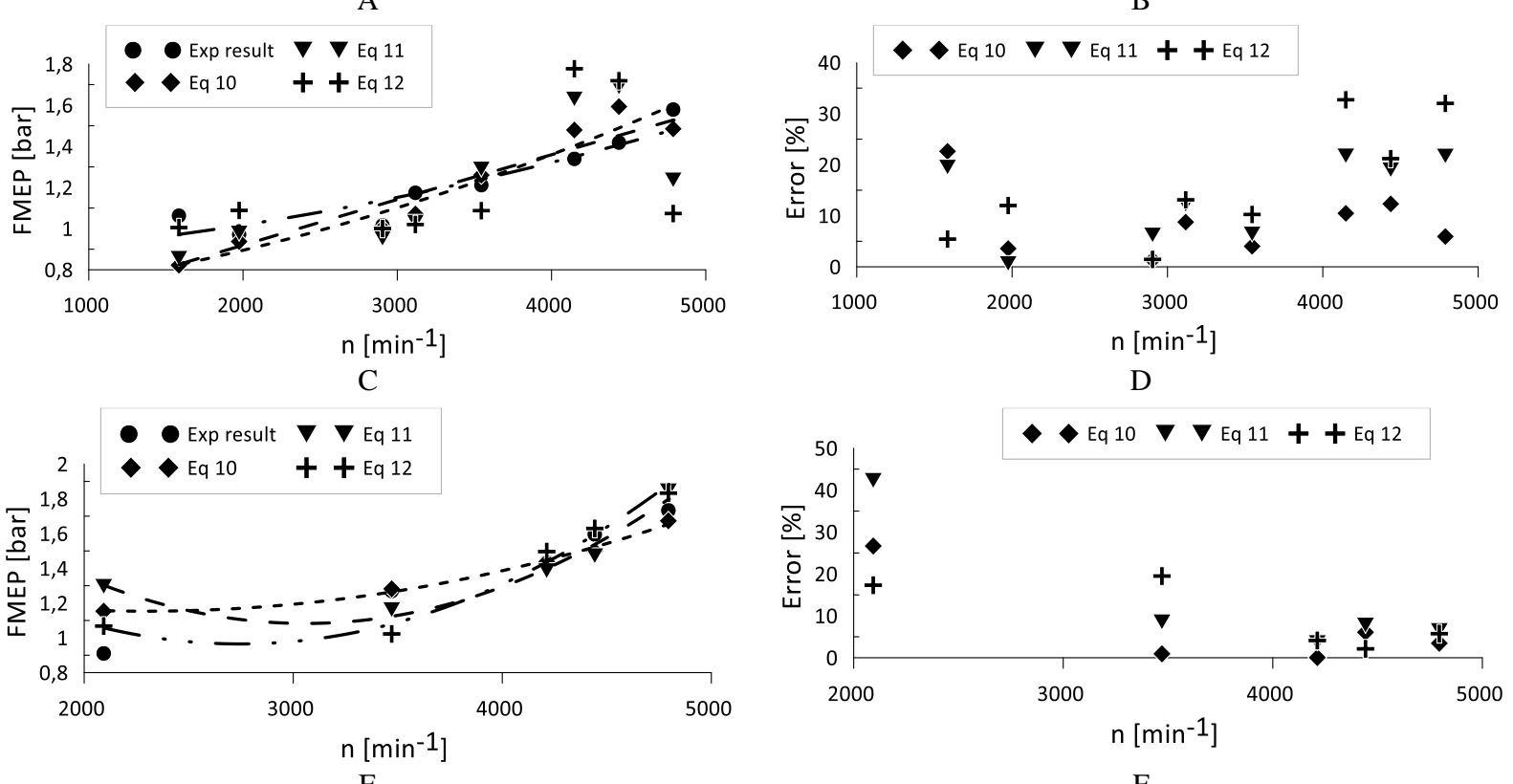

$\mathrm{D}$

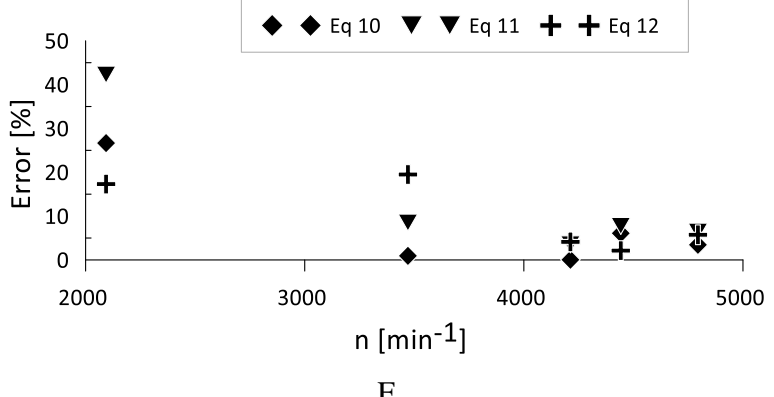

Fig. 9. FMEP calculated by proposed correlations. A. $25 \%$ load, B. error percentage $25 \%$ load, C. $50 \%$ load, D. error percentage $50 \%$ load, E. $100 \%$ load, F. error percentage $100 \%$ load.

\section{CONCLUSIONS}

The mechanical losses determined by the indicated diagram method and the contributions of the pumping and friction and auxiliary losses were characterized and analysed on a single-cylinder ICE Robin EY15 under different rotation speeds and loads.

The effective engine performance was characterized. The maximum torque and BMEP were $5.14 \mathrm{Nm}$ and 4.5 bar at $2100 \mathrm{~min}^{-1}$, respectively, and the maximum power was $1.77 \mathrm{~kW}$ at $4200 \mathrm{~min}^{-1}$ at full load. The minimum specific fuel consumption was $403.3 \mathrm{~g} / \mathrm{kWh}$ at $2900 \mathrm{~min}^{-1}$. The maximum net efficiency was 0.208 (20.8\%), and the minimum was $0.03(3 \%)$; therefore, it was concluded that $79.2 \%-97 \%$ and of the energy provided by the fuel is dissipated in the form of heat at the tested operation points.

The engine mechanical efficiency was determined. The engine FMEP ranges from 0.91 bar at $2100 \mathrm{~min}^{-1}$ to 1.73 bar at $4800 \mathrm{~min}-1$ under the full load conditions. It was concluded that the FMEP represents $16.8 \%-77.5 \%$ of the IMEP for the evaluated operation points, which is used for overcoming the different losses.

The pumping losses contribution to the total mechanical losses was analysed. Under the full load conditions, the PMEP contributes between $18 \%$ at $2100 \mathrm{~min}^{-1}$ and $40.6 \%$ at $4200 \mathrm{~min}^{-1}$ of the FMEP. However, the PMEP contribution increases, reaching a maximum of $58.8 \%$ of the FMEP at $2500 \mathrm{~min}^{-1}$ and $25 \%$ load, which is higher than the maximum contribution mentioned in other referred studies. This is because the pulsation suppressor tank installed in the intake generates an additional air flow restriction, causing a higher vacuum pressure. However, the sum of the RMEP and AMEP contributions ranges between $82 \%$ and $41.2 \%$ of the FMEP, having greater relevance as the regime or load increases.

The experimental FMEP results were compared with those calculated using some correlations available in the literature. The error percentages were lower than $34.2 \%, 32.3 \%$, and $26.3 \%$ for load levels of 25,50 , and $100 \%$, respectively, using the Gish et al. [13], Fujii et al. [19], and Yagi et al. [18] correlations, respectively. It is clarified that the test conditions of the correlations were different from the Robin EY15 engine test conditions.

Three empirical correlations dependent on the rotation speed and variables sensitive to load variation, such as the BMEP, maximum in-cylinder pressure, and mean intake pressure, were obtained to determine the engine mechanical efficiency. The FMEP calculated using these correlations was 
compared with the experimental FMEP. The error percentages were less than $33.6 \%, 32 \%$, and $42.3 \%$ for load levels of $25 \%, 50 \%$, and $100 \%$ using equations (10)-(12), respectively. However, for speeds between 2000 and $3550 \mathrm{~min}^{-1}$ at $50 \%$ load, the error was less than $13.1 \%$, and for speeds above $3500 \mathrm{~min}^{-1}$ at full load, it was less than $19.5 \%$.

\section{ACKNOWLEDGEMENTS}

The authors thank the Universidad Tecnológica de Pereira UTP (Technological University of Pereira) for their support throughout the research and to the Colombian "Departamento Administrativo de Ciencia, Tecnología e Innovación Colciencias" for supporting the project entitled: "Desarrollo de un sistema de monitoreo para el análisis energético y de condición de emisiones en motores de combustión interna diésel con base en técnicas no intrusivas" ("Develop-ment of a monitoring system for energy analysis and emis-sion condition in diesel internal combustion engines based on non-intrusive techniques") code 1110-776- 57801, through which the research described in this article was developed.

\section{REFERENCES}

1. Heywood J. Internal combustion engine fundamentals. McGraw-Hill. 1988.

2. Tormos B, Ramírez L, Johansson J, Björling M, Larsson R. Fuel consumption and friction benefits of low viscosity engine oils for heavy duty applications. Tribology International. 2017;110(6): 23-34. http://dx.doi.org/10.1016/j.triboint.2017.02.007

3. Cruz-Peragón F, Palomar J, Díaz F, JiménezEspadafor F. Fast on-line identification of instantaneous mechanical losses in internal combustion engines. Mechanical Systems and Signal Processing. 2010;24(1):267-280.

http://dx.doi.org/10.1016/j.ymssp.2009.06.009

4. Tormos B, Martín J, Carreño R, Ramírez L. A general model to evaluate mechanical losses and auxiliary energy consumption in reciprocating internal combustion engines. Tribology International. 2018;123(7):161-179.

https://doi.org/10.1016/j.triboint.2018.03.007

5. Wong $\mathrm{V}$, Tung S. Overview of automotive engine friction and reduction trends-Effects of surface, material, and lubricant-additive technologies. Friction. 2016;4:1-28.

https://doi.org/10.1007/s40544-016-0107-9

6. Sgroi M, Asti M, Gili F, Deorsola F, Bensaid S, Fino D, Kraft G, García I, Dassenoy F. Engine bench and road testing of an engine oil containing MoS2particles as nano-additive for friction reduction. Tribology International. 2017;105(1): 317-325.

http://dx.doi.org/10.1016/j.triboint.2016.10.013

7. Thring RH. Engine friction modeling. SAE Technical Paper. 1992:(0920482).

https://doi.org/10.4271/920482

8. Kumar V, Sinha S, Agarwal A. Tribological studies of an internal combustion engine. In: Agarwal A, Gupta J, Sharma N, Singh A. (eds) Advanced engine diagnostics. Energy, Environment, and
Sustainability. Springer, Singapore; 2019. https://doi.org/10.1007/978-981-13-3275-3_12

9. Tormos B, Martín J, Pla B, Jiménez-Reyes A. A methodology to estimate mechanical losses and its distribution during a real driving cycle. Tribololy International. 2020;145(5):106208. https://doi.org/10.1016/j.triboint.2020.106208

10. Arsie I, Pianese C, Rizzo G, Flora R, Serra G. Development and validation of a model for mechanical efficiency in a spark ignition engine. SAE Technical Paper. 1999; (1999-01-0905). https://doi.org/10.4271/1999-01-0905

11. Fang C, Meng X, Xie Y, Wen C, Liu R. An improved technique for measuring piston-assembly friction and comparative analysis with numerical simulations: Under motored condition. Mechanical Systems and Signal Processing. 2019;115:657-676. https://doi.org/10.1016/j.ymssp.2018.06.015

12. Noorman M, Assanis D, Patterson DJ. Overview of techniques for measuring friction using bench tests and fired engines. SAE Technical Paper. 2000; (2000-01-1780). https://doi.org/10.4271/2000-01-1780

13. Koch F, Geiger U, Hermsen F. PIFFO - Piston friction force measurements during engine operation. SAE Technical Paper. 1996; (960306). https://doi.org/10.4271/960306

14. Millington B, Hartles E. Frictional losses in diesel engines. SAE Technical Paper. 1968; (680590). https://doi.org/10.4271/680590

15. Gish R, Mccullough J, Retzloff J, Mueller H. Determination of true engine friction. SAE Technical Paper. 1958;(580063). https://doi.org/10.4271/580063

16. Wakuri Y, Soejima M, Ejima Y, Hamatake T, Kitahara T. Studies on friction characteristics of reciprocating engines. SAE Technical Paper. 1995; (952471). https://doi.org/10.4271/952471

17. Shelby M, Stein R, Warren C. A new analysis method for accurate accounting of IC engine pumping work and indicated work. SAE Technical Paper. 2004; (2004-01-1262).

https://doi.org/10.4271/2004-01-1262

18. Skjoedt M, Butts R, Assanis DN, Bohac S V. Effects of oil properties on spark-ignition gasoline engine friction. Tribology International. 2008;41(6):556563. https://doi.org/10.1016/j.triboint.2007.12.001

19. Mufti R. Total and Component Fricition in a Motored and Firing Engine. 2004.

20. Yagi S, Ishibasi Y, Sono H. Experimental analysis of total engine friction in four stroke S. I. engines. SAE Technical Paper. 1990; (900223). https://doi.org/10.4271/900223

21. Fujii I, Yagi S, Sono H, Kamiya H. Total Engine Friction in Four Stroke SI Motorcycle Engine. SAE Technical Paper. 1988;(880268). https://doi.org/10.4271/880268

22. Ciulli E. Review of internal combustion engine losses. Part 2: Studies for global evaluations. Proceedings of the Institution of Mechanical Engineers, Part D: Journal of Automobile Engineering. 1993;207(3):229-240. https://doi.org/10.1243/PIME_PROC_1993_207_18 4_02

23. Rezeka S, Henein N. A new approach to evaluate instantaneous friction and its components in internal combustion Engines. SAE Technical Paper. 1984; ( 840179). https://doi.org/10.4271/840179 
24. Patton KJ, Nitschke RC, Heywood JB. Development and evaluation of a friction model for spark-ignition engines. SAE Technical Paper. 1989; (890836). https://doi.org/10.4271/890836

25. Lee S, Kang J, Park S. Measurement and modeling of crank train friction in light-duty diesel engines. Journal of Mechanical Science and Technology. 2020;34(2):889-903. https://doi.org/10.1007/s12206-020-0139-y

Received 20xx21-03-12

Accepted 2021-08-12

Available online 2021-08-13
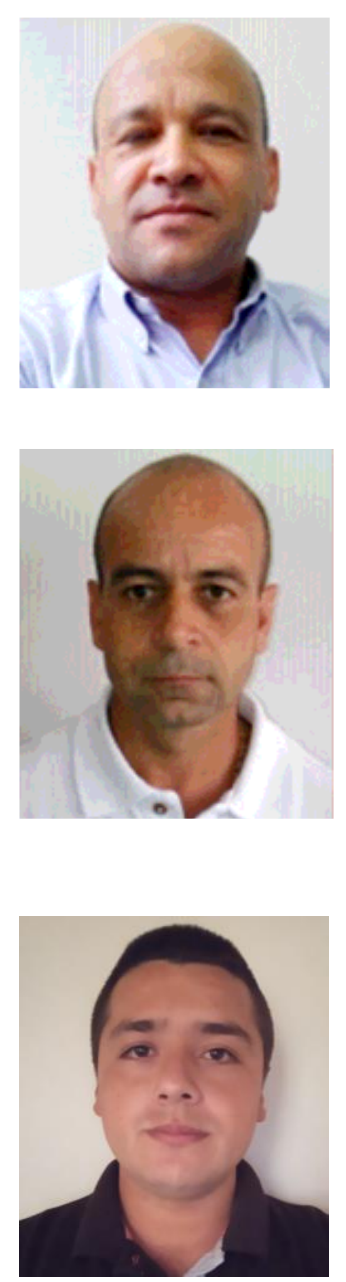

Carlos ROMERO received Ph.D. degree in Mechanical Engineering from Valencia Polytechnic University, Valencia, Spain, in 2009. Now he works at Pereira Technological University. His current research interests include internal combustion machine, and machine design.

Edison HENAO received Ph.D. degree in Engineering from Pereira Technological University, Pereira, Colombia, in 2021. Now he works at Pereira Technological University His current research interests include mechanisms analysis, Internal combustion machine, and machine design.

Juan RAMÍREZ received Mechanical Engineer degree from Pereira Technological University, Pereira, Colombia, in 2017. Now he works at Pereira Technological University and he is Mechanical Engineering M.Sc. student at Pereira Technological University. His current research interests include Internal combustion machine, and machine design. 